\title{
Fontes de informação na cobertura da posse presidencial de Jair Bolsonaro pela imprensa brasileira ${ }^{1}$
}

\section{Sources of information regarding the coverage of the presidential inauguration of Jair Bolsonaro in Brazilian press}

Terezinha Silva², Gislene Silva, Daiane Bertasso Ribeiro4, Rafael Rangel

Winch $^{5}$ e Anaíra Sousa de Moraes Sarmento ${ }^{6}$

Agradecemos ao Conselho Nacional de Desenvolvimento Científico e Tecnológico (CPNq), à Coordenação de Aperfeiçoamento de Pessoal de Nível Superior (Capes), à Fundação de Amparo à Pesquisa e Inovação de Santa Catarina (Fapesc) e à Pró-Reitoria de Pesquisa da Universidade Federal de Santa Catarina (UFSC) pelos apoios que colaboraram para a realização de nossas pesquisas, das quais este trabalho é parte. Programa de Pós-Graduação em Jornalismo da Universidade Federal de Santa Catarina (UFSC) e uma das líderes do grupo de pesquisa Transverso da UFSC. E-mail: terezinhasilva@yahoo.com. Programa de Pós-Graduação em Jornalismo da UFSC e uma das líderes do grupo de pesquisa Transverso da UFSC. E-mail: gislenedasilva@gmail.com. Programa de Pós-Graduação em Jornalismo da UFSC e uma das líderes do grupo de pesquisa Transverso da UFSC. E-mail: daianebertasso@gmail.com. da UFSC. Bolsista Fapesc. E-mail: rafael16@hotmail.com. 


\section{Resumo}

Este artigo estuda e problematiza o uso de fontes de informação na cobertura jornalística sobre a posse de Jair Bolsonaro na presidência da República, em $1^{\circ}$ de janeiro de 2019. Busca-se compreender de que modo a escolha de fontes condiciona o resultado da cobertura sobre a posse presidencial realizada pelos jornais Folha de S.Paulo, O Estado de $S$. Paulo e $O$ Globo, pelos portais UOL e G1 e pelas revistas Carta Capital, Época, IstoÉ e Veja. A análise de 208 textos evidencia e discute três principais problemas: a predominância de visões e posições de fontes oficiais, a baixa diversidade de atores da sociedade civil, e a não identificação de fontes.

Palavras-chave

Jornalismo e política, cobertura jornalística, fontes de informação, posse de Jair Bolsonaro.

\section{Abstract}

This article studies and problematizes the use sources of information in news coverage regarding the inauguration of Jair Bolsonaro in the presidency of the Republic, January $1^{\text {st }}, 2019$, in Brazil. The study seeks to understand how the choice of sources conditioned the coverage version of the presidential inauguration published by newspapers Folha de S.Paulo, O Estado de S. Paulo, and O Globo, the sites UOL and G1, and the magazines Carta Capital, Época, IstoÉ, and Veja. The analysis of 208 texts highlights and discusses three main problems: the predominance of official sources and perspectives, the low diversity of civil society actors, and the use of unidentified sources.

\section{Keywords}

Journalism and politics, news coverage, sources of information, inauguration of Jair Bolsonaro. 


\section{Introdução}

As relações entre o poder e a mídia hegemônica são históricas, de dependência mútua, e se refletem no tipo de cobertura jornalística realizada. A escolha das fontes que compõem os noticiários tem um papel estratégico, uma vez que define quem terá a voz amplificada, se haverá pluralidade nas perspectivas, de que forma as pessoas serão ouvidas, qual o lugar reservado à fala dos entrevistados na narrativa construída, quais documentos vão ser acessados, quais conteúdos e interpretações chegarão à sociedade. Uma série de valores e de posturas políticoideológicas permeia tal processo, fazendo parte de um movimento que é sempre de mão dupla, pois a mídia tanto participa da construção da realidade quanto se retroalimenta dessa construção, na qual seu trabalho e atuação ainda servem como instrumento de luta pelo poder (MOTTA, 2002, p. 13).

A chegada de Jair Bolsonaro à presidência da República, em janeiro de 2019, aconteceu em um contexto de significativa polarização política e social, após o golpe contra a presidente Dilma Rousseff, de intensas críticas de parte da sociedade à postura da imprensa no desenrolar do processo que levou à derrubada da presidenta, e de uma poderosa indústria de fake news, cujos tentáculos estão atualmente sob investigação judicial. Desde a chegada de Bolsonaro ao poder, há no país uma escalada de políticas neoliberais, de destruição de direitos e de políticas de proteção trabalhista, social, ambiental etc., além do avanço de discursos e práticas de extrema-direita que ameaçam a democracia brasileira e as possibilidades de convivência social e de respeito às diferenças.

Tal contexto nos motivou a pesquisar como as fontes escolhidas na apuração jornalística afetaram o resultado da cobertura da posse de Jair Bolsonaro. Consideramos o uso de fontes como a base fundamental das estratégias para captação da informação, destacando a correlação direta entre fontes escolhidas e narrativas e discursos jornalísticos. Há uma inseparabilidade entre as práticas de apuração, a adoção de determinadas fontes e o acontecimento configurado pela cobertura jornalística (SILVA et al., 2020). 
[...] uma cobertura jornalística envolve tanto as estratégias de apuração, composição e angulação dos assuntos nos materiais produzidos por repórteres e editores, e comumente classificados como sendo informativos/ interpretativos (notas, notícias/matérias, reportagens, perfis), quanto o conjunto de produções explicitamente opinativas (editorial, colunas, artigos, blogs etc.) que colaboram para a compreensão do tema ou acontecimento tratado (SILVA et al., 2020, p. 9-10).

Neste estudo, que é parte de uma pesquisa mais ampla ${ }^{1}$, nosso interesse se volta para as escolhas das mídias em visibilizar determinados relatos ou em deixar fontes ausentes do debate público em um momento em que já se manifestavam graves danos à democracia brasileira. Analisamos as fontes do noticiário produzido nos dias $1^{\circ}$ e 2 de janeiro de 2019 pelos jornais impressos Folha de S.Paulo, O Estado de S. Paulo e O Globo e os portais UOL e G1. Analisamos ainda as edições das revistas semanais Veja, Carta Capital e Istoé em período e cobertura correspondentes - última semana de 2018 e primeira edição de janeiro de 2019. O material empírico totalizou 208 textos.

\section{Fontes, poder e interesse público}

A discussão sobre fontes no jornalismo remete, inevitavelmente, às relações entre os agentes da instância midiática - organizações de mídias e seus profissionais - e os atores do poder político-econômico; por isso, remete também às contradições envolvendo o princípio do interesse público como um dos fundamentos do jornalismo. Mesmo após a passagem da imprensa de opinião à fase de produção noticiosa em empresa capitalista, orientada também ao lucro e ao interesse privado, há mais de dois séculos, o interesse público se mantém como o grande sustentáculo do discurso de autolegitimação do jornalismo enquanto 
instituição social, como nos lembra Wilson Gomes (2009). Tal discurso afirma que o jornalismo se justifica porque serve ao interesse público, à cidadania, à formação da opinião pública, e é fundamental ao debate público e à democracia.

O paradoxo entre esse ideal normativo que coloca o interesse público como valor supremo do jornalismo e a prática jornalística concretizada em empresas privadas, cuja atuação é movida também pelo interesse privado e por intrincadas relações com grupos hegemônicos na sociedade, é tema que permeia parte significativa da tradição de estudos na área. A partir dos anos 1960, estudos clássicos do jornalismo trataram desse vínculo da imprensa com as elites política e econômica, destacando como as fontes selecionadas para informar e interpretar os fatos condicionaram a cobertura jornalística. Se o pressuposto é que o jornalismo tem um compromisso com o interesse público e com a cidadania, quem são os atores acionados para definir os contornos do que seria de interesse público nas notícias disponibilizadas para o debate coletivo?

Na chamada teoria da ação política, especialmente na abordagem de Edward S. Herman e Noam Chomski, com seus estudos sobre a imprensa norte-americana no contexto da Guerra Fria (TRAQUINA, 2005), já se apontava a dependência dos jornalistas em relação a fontes do governo e do mundo empresarial como um dos cinco fatores explicativos da submissão dos meios de comunicação aos interesses do sistema capitalista. Para esses autores, as notícias têm um papel propagandístico e ideológico, o que contribuiria para reforçar os pontos de vista do establishment.

Orientadas por outro paradigma e pressupostos, as chamadas teorias construcionistas do jornalismo (estruturalista e interacionista) também lançaram luz, já nos anos 1960 e 1970, sobre esse ponto nevrálgico da relação entre jornalistas e fontes com alto prestígio social e poder. Tais teorias questionam as abordagens instrumentalistas ou da ação política e seus pressupostos - a produção noticiosa como conspiração entre agentes sociais e a distorção intencional das notícias. Sua ênfase está na importância das rotinas profissionais criadas pelos jornalistas para realizarem o trabalho ante condicionantes organizacionais ou 
contextuais, como as horas de fechamento da produção noticiosa e a quantidade de ocorrências a selecionar como notícia (TRAQUINA, 2005). Ambas entendem que as notícias são o resultado de complexos processos de interação entre agentes sociais: os jornalistas com suas fontes, com a sociedade e com os demais jornalistas - dentro ou fora de sua organização midiática. As duas perspectivas destacam a sensível relação entre jornalistas e fontes do poder, mas de maneiras particulares. A abordagem estruturalista enfatiza o papel das mídias na reprodução das ideologias dominantes, embora reconheça, ao contrário da teoria da ação política, a relativa autonomia dos jornalistas em relação a um controle econômico direto sobre a produção noticiosa. Nessa perspectiva teórica, no entanto, mesmo involuntariamente (HALL et al., 1993), os meios se transformariam em instrumentos de controle social - um aparelho ideológico do Estado (ALTHUSSER, 1998). Como parte da indústria cultural, as notícias assim colaboram para a hegemonia ideológica na sociedade (TRAQUINA, 2005).

Ao tratarem da construção social da notícia, Hall et al. (1993) estabelecem a distinção entre "definidores primários" e "definidores secundários". Para os autores, definidores primários são aqueles atores que primeiro definem o sentido para os acontecimentos, e, por conta do poder, da fácil acessibilidade aos meios de comunicação e posição de destaque em uma hierarquia de credibilidade, conseguem condicionar todas as interpretações posteriores. Assim, mesmo que os meios não estejam a serviço dos poderosos, reproduzem seus discursos adaptados à linguagem da notícia, fazendo que impressões particulares da sociedade pareçam ser do interesse de todos. Desta forma, contribuem para a manutenção de uma hegemonia ideológica na sociedade. Nesse processo, aspectos de produção da notícia, como pressão contra o tempo e necessidade de imparcialidade e objetividade, também seriam importantes e, de maneira combinada, facilitariam aos definidores primários o "exagerado acesso sistematicamente estruturado aos media" (Hall et al., 1993, p. 229, grifo do autor).

A predominância dos definidores primários, assim como a autonomia e poder dos próprios jornalistas na definição e interpretação do que é noticiado, 
também são reconhecidos pela perspectiva interacionista. Esta, porém, aponta a possibilidade de outros agentes - inclusive aqueles de menor capital econômico, político, social e cultural - também mobilizarem o campo jornalístico para suas atividades comunicacionais. Em certas situações, poderiam até vencer disputas interpretativas sobre acontecimentos e temas controversos (TRAQUINA, 2005). De qualquer modo, o acesso às mídias hegemônicas favorece aos que detêm mais poder na sociedade. A acessibilidade é facilitada não apenas por interesses, ideologias e sentidos compartilhados sobre o mundo, mas pela própria forma de distribuição da "rede noticiosa" (TUCHMAN,1983), que organiza a rotina de produção jornalística no tempo e no espaço, a exemplo das sedes de governos, Congresso Nacional, Assembleias Legislativas, Federações de Indústrias, Supremo Tribunal Federal etc., já pré-determinando as ocorrências noticiáveis e os atores que as interpretarão.

As mídias hegemônicas e o jornalismo nelas praticado possuem, portanto, um papel ambíguo na cobertura e no debate dos assuntos de interesse público. Ao mesmo tempo que podem expandir sua visibilidade, publicidade e discussão, podem ainda reforçar distinções de poder entre os atores ao restringir o acesso de parte da sociedade civil, assim como suas questões e interpretações, além de facilitar a expressão de interesses e perspectivas de agentes do poder (MAIA, 2006). A profissionalização das fontes, sobretudo a partir dos anos 2000, tem reforçado a luta competitiva e desigual para acessar as mídias e influenciar a produção noticiosa e a interpretação de acontecimentos e temas públicos. Por outro lado, a internet tornou o ecossistema midiático mais complexo e menos dependente da mediação jornalística para a comunicação dos diferentes sujeitos sociais com distintos públicos. Cada vez mais variados atores - de políticos a ativistas e associações civis de diversos tipos - têm usado seus sites e perfis em redes sociais digitais para divulgar seus próprios conteúdos e interpretações (MARQUES; REBOUÇAS, 2019; ZILLER; TEIXEIRA, 2018), constituindo as chamadas mídias das fontes (SANT'ANNA, 2009). Estas, por sua vez, podem reverberar na cobertura jornalística - um espaço de visibilidade ainda importante e disputado, em razão de seu poder de legitimação de conteúdos e amplificação a variados públicos. 


\section{A centralidade das fontes na cobertura jornalística}

As fontes de informação situam-se no centro de toda cobertura jornalística. De acordo com Pinto (2000, p. 278), "as fontes são pessoas, são grupos, são instituições sociais ou são vestígios - falas, documentos, dados - por aqueles preparados, construídos, deixados". Ainda segundo o autor, as fontes indicam posições e relações sociais, além de expressarem interesses e pontos de vista. Paul Lashmar (2019) também enfatiza a centralidade das fontes no resultado final dos produtos jornalísticos. Esse vínculo entre o que as fontes expressam e o teor do conteúdo publicado deriva, sobretudo, de como os jornalistas se relacionam com os seus informantes. "Os jornalistas são altamente dependentes das fontes e, se os relacionamentos fonte-jornalista parecerem simples como uma transferência unidirecional de informações, na prática, pode haver muitos níveis e complexidades no relacionamento" (LASHMAR, 2019, p. 1). Sendo um elemento basilar das narrativas veiculadas pelo jornalismo, as fontes podem ser acionadas em várias etapas da produção noticiosa, principalmente ao longo da apuração, processo marcado pela coleta de informações, cruzamento de dados e checagem de fatos. Como observa Patrick Charaudeau (2006), o jornalismo possui dupla responsabilidade ao "obter os meios de aceder a um máximo de fontes possíveis: verificá-las e apresentá-las" (p. 147).

Pesquisas sobre fontes jornalísticas têm longa tradição nos estudos da área, como mencionado no tópico anterior. O levantamento de Jorge Pedro de Sousa (2002) observa que elas oscilam entre uma visão que enfatiza a ideia de negociação do sentido para os acontecimentos entre jornalistas e fontes e uma visão mais pessimista, que vê o sentido dos acontecimentos como sendo previamente determinado, sobretudo quando as fontes detêm algum tipo de poder (SOUSA, 2002). Neste elenco de alguns autores e suas teorias, mapeados por Sousa, podemos ver a grande diversidade de questões implicadas na relação repórter e fonte. Resumidamente, seriam estas: em Leon Sigal (1973), são apontados os canais informativos de rotina, os informais e os de iniciativa dos próprios jornalistas. Em Gans (1979), as fontes informativas, institucionais, oficiosas e provisórias, 
as passivas e ativas e as conhecidas e desconhecidas; a inércia das organizações noticiosas versus a atividade de fontes interessadas; a dominância de fontes por seu poder; credibilidade e proximidade com os jornalistas e, ainda, a escolha de fontes em função de seu posicionamento na estrutura social, de sua conveniência, fiabilidade, respeitabilidade e também em termos de necessidades e capacidade de produção da informação. Em Schlesinger (1992), enfatizam-se as táticas das fontes para ter acesso aos veículos por cativação e sensibilização dos jornalistas; seleção apropriada de meios-alvo; fornecimento de informações capazes de corresponder aos critérios de noticiabilidade e às convenções de jornalistas. Em Blumer e Gurevich (1995), há a discussão do conceito de fonte, que os autores consideram ambíguo e amplo, sinalizando a existência de diferenças entre fonte individual e fonte institucional, bem como a relação entre jornalistas e políticos, assentada em direitos e obrigações mútuas. Para Curran (1996), existem variações de pressão sobre os meios jornalísticos, do topo para a base, quando jornalistas se aproximam dos grupos socialmente dominantes, e da base para o topo, ao se aproximarem dos grupos sociais de base. Em Pinto (1997), há o destaque para a atuação do marketing político sobre os procedimentos jornalísticos, bem como a coexistência de conflito e cumplicidade entre jornalistas e fontes políticas, além de o autor observar o declínio de fontes identificadas em favor de fontes anônimas. Por fim, em Santos (1997), encontra-se o problema de as fontes burocratizadas tenderem a manter permanente disponibilidade de atendimento aos jornalistas, traçando antecipadamente a ocorrência de acontecimentos e, ainda, os espaços de cooperação, negociação e luta entre as partes, uma vez que objetivos de fontes e de jornalistas nem sempre coincidem.

Há autores que destacam outros tipos de fontes e aspectos que marcam a relação entre informantes e jornalistas. Michael Kunczik (2001) sintetiza as fontes em três grandes categorias: as de elite social, as que carecem de posição especial na sociedade e as fontes anônimas. Já Furio Colombo (1998) discute as fontes opacas, representadas por aquelas que não são transparentes, em que não há explicitação nem confirmação da informação, e as fontes credíveis, 
que dão vistosa paternidade à informação. Miguel Alsina (2009), por seu turno, enfatiza outros elementos da produção noticiosa, como a desigualdade no acesso ao circuito da informação entre os agentes sociais, as estratégias que as fontes utilizam para influenciar o trabalho dos jornalistas; e ainda os jornalistas que podem subornar ou ludibriar suas fontes.

Perpassa estes estudos a problemática da diversidade das fontes como determinantes para coberturas que levam em consideração a importância da pluralidade de sujeitos e perspectivas na narrativa jornalística. No entanto, como pondera Carlos Jauregui (2018), a mera consulta a diferentes fontes não deve ser interpretada, necessariamente, como sinônimo de pluralidade. "Em muitas situações, diferentes pessoas são convocadas numa matéria para endossar uma mesma tese sobre algum assunto. Por outro lado, há reportagens com um número reduzido de fontes que conseguem apresentar maior variedade de perspectivas" (JAUREGUI, 2018, p. 56).

O tema também é abordado por Joana Ziller e Nísio Teixeira (2018). Eles explicam que a busca pela pluralidade de vozes na produção de notícias está entre um dos três eixos que se complementam durante a apuração: 1) verificação; 2) fontes e personagens; e 3) pesquisa. No primeiro eixo, inicia-se o contato com o fenômeno que se quer conhecer, entendendo suas implicações e contornos. No segundo, o jornalista inicia o contato com as fontes; busca idealmente uma diversidade delas, no sentido de proporcionar uma pluralidade de vozes e perspectivas político-ideológicas, além de garantir a polifonia do conteúdo a ser publicado. Por fim, o terceiro eixo corresponde à pesquisa de dados e à checagem deles. "A busca por documentos e pesquisas, além de entrevistas, são métodos tradicionais de apuração" (ZILLER; TEIXEIRA, 2018, p. 42). Os pesquisadores sinalizam que, apesar da busca ideal por diferentes perspectivas, a pressão do tempo do fechamento das edições e a percepção do que é possível ou não fazer, dentro do prazo de apuração e edição, interfere na definição das fontes procuradas (ZILLER; TEXEIRA, 2018, p. 43). 


\section{Procedimentos metodológicos}

É dentro da intrincada problemática das correlações de forças entre jornalistas e fontes que empreendemos análises de materiais empíricos coletados em veículos da imprensa hegemônica no contexto específico da polarização política e dos riscos à democracia brasileira configurados pela chegada de Jair Bolsonaro à presidência da República, em janeiro de 2019. Deste quadro vêm nossas motivações em pesquisar como as fontes escolhidas na apuração jornalística afetam o resultado da cobertura da posse de Bolsonaro. Este estudo é parte de uma pesquisa mais ampla, concluída no primeiro semestre de 2021 . Analisamos as fontes do noticiário produzido nos dias $1^{\circ}$ e 2 de janeiro de 2019 pelos jornais impressos Folha de S.Paulo, O Estado de S.Paulo e O Globo, pelos portais UOL e G1 e as edições das revistas semanais Veja, Carta Capital e Istoé em período e cobertura correspondentes (última semana de 2018 e primeira edição de janeiro de 2019). O material empírico reúne 78 unidades informativas dos três jornais impressos, 86 dos dois portais e 34 das três revistas semanais, totalizando 208 textos.

Elaboramos uma tipologia de fontes organizadas em 11 categorias que contemplam naturezas diferentes do que nomeamos como fontes. Assim, incluise tanto os atores a quem alguns costumam restringir o termo fonte (as pessoas entrevistadas) quanto os materiais que servem como fonte para obtenção de informação no processo de apuração (documentos, arquivos, estudos ou outras mídias, por exemplo). São estas as categorias: Entrevistados, que reúne as subcategorias de Autoridades públicas, Cidadãos, Especialistas e Celebridades, identificadas na cobertura; Repórter observador; Documentos, Arquivos/Estudos, ou seja, pesquisa interna à própria mídia e externa; Coletiva de imprensa; Assessoria de imprensa; Declarações em função do cargo, que não se trata de fonte entrevistada, mas de informações fornecidas não especificamente para uma mídia e nem em coletiva de imprensa agendada, e sim por meio de notas publicadas; Agências de notícias; Redes sociais digitais; Outros veículos/outros jornalistas; e, ainda, Fontes não especificadas ou não identificadas. Nosso interesse foi observar como a maior ou menor incidência destas fontes nos textos revela 
estratégias para captação da informação, indícios e marcas de apuração, aspectos do processo produtivo da notícia e, por fim, a ingerência político-ideológica sobre tais escolhas editoriais.

\section{Fontes mais utilizadas na cobertura de posse de Jair Bolsonaro em jornais, portais e revistas}

Jornais

Na cobertura jornalística² realizada pelos jornais impressos Folha de S. Paulo, O Estado de S. Paulo e O Globo sobre a posse presidencial de Jair Bolsonaro observou-se, no conjunto dos três veículos, um total de 78 unidades informativas publicadas nos dias $1^{0}$ e 2 de janeiro de 2019. Na Folha de S.Paulo foram 28 matérias (12 e 16, respectivamente); em O Estado de S. Paulo, 26 (12 e 14, respectivamente); e, em O Globo, 24 (4 e 20, respectivamente).

Folha de S.Paulo recorreu a 50 Entrevistados, entre Autoridades públicas (19), Cidadãos (17) e Especialistas (14). Próxima a estas ocorrências, tem-se também a apuração de informações retiradas de Arquivos/Estudos (15), feita em publicações anteriores do próprio jornal. As fontes do tipo Cidadãos aparecem em apenas oito dos 28 materiais informativos do jornal, dos quais apenas um traz cinco fontes desse tipo. Os Especialistas estão presentes em somente seis dos 28 materiais informativos da cobertura.

O Estado de S. Paulo apresentou 31 Entrevistados - sendo 19 Autoridades públicas, 8 Cidadãos, 3 Especialistas e 1 Celebridade. O veículo recorreu também, nestas duas edições, a Documentos (20) e Arquivos/Estudos (11). Nesse impresso, as oito ocorrências de fontes do tipo Cidadãos localizam-se em apenas dois materiais. O oficialismo da cobertura se deve, sobretudo, ao expressivo espaço dado às Autoridades e aos Documentos. Outra situação que chama a atenção 
é a baixa presença de Especialistas, aparecendo apenas três vezes dentro das 26 unidades noticiosas analisadas.

Já O Globo recorreu a 35 entrevistados, entre Especialistas (17), Autoridades públicas (13) e Cidadãos (5). Próxima a estas ocorrências, observa-se que, em 20 unidades, o jornal usou o recurso do Repórter observador e que informações também foram retiradas de Arquivos/Estudos (11) - ou seja, a partir de publicações anteriores do próprio jornal -, assim como de Documentos (10). Por outro lado, destaca-se reduzido número de Cidadãos (5) entrevistados.

Considerando a cobertura dos três jornais (Quadro 1), dentre os 116 entrevistados, há presença predominante de Autoridades públicas (51), seguidas de Especialistas (34) e Cidadãos (30). Verifica-se significativa recorrência a Documentos: 39 registros de informações retiradas de discursos e pronunciamentos oficiais ou de documentos como medidas provisórias, decretos e leis. Há ainda a recorrência a Arquivos/Estudos, que somaram 37 registros, bem como a coleta de informações por observação direta do Repórter (30). No conjunto dos três veículos, impressiona a quantidade de Fontes não especificadas/identificadas (33). Chama atenção, também, que as marcas de informações retiradas de Redes sociais (17) estão próximas das extraídas de materiais fornecidos por Assessorias de imprensa. Vale ressaltar que as muitas fontes não especificadas/identificadas podem conter informações provavelmente vindas de assessorias.

Quadro 1: Fontes utilizadas na cobertura dos jornais

\begin{tabular}{|l|c|c|c|c|}
\hline \multicolumn{1}{|c|}{ Tipos de fonte } & Folha de S.Paulo & O Estado de S. Paulo & O Globo & TOTAIS \\
\hline Entrevistados & 50 & 31 & 35 & 116 \\
\hline Documentos & 9 & 20 & 10 & 39 \\
\hline Arquivos/Estudos & 15 & 11 & 11 & 37 \\
\hline Fontes não especificadas & 6 & 14 & 13 & 33 \\
\hline Repórter observador & 2 & 8 & 20 & 30 \\
\hline Assessoria de imprensa & 2 & 8 & 11 & 21 \\
\hline Redes Sociais & 4 & 8 & 5 & 17 \\
\hline Outros veículos/Outros jornalistas & 4 & 0 & 4 & 8 \\
\hline Declarações em função do cargo & 3 & 5 & 0 & 8 \\
\hline Coletiva de imprensa & 0 & 0 & 0 & 0 \\
\hline Agência de notícias & 0 & 0 & 0 & 0 \\
\hline
\end{tabular}


Revistas

Para a análise da cobertura jornalística da chegada do novo governo ao poder realizada por revistas semanais de informação, foram consultadas as edições impressas das revistas Carta Capital, Época, IstoÉ e Veja referentes à última semana completa do ano de 2018 (entre 24 e 29 de dezembro) e à primeira edição de janeiro de 2019 (entre os dias $1^{\circ}$ e 9). Após a análise da cobertura destas revistas, percebeu-se que o gênero jornalístico opinativo teve incidência similar ao gênero informativo, já que dos 68 textos publicados nas quatro publicações foram 34 informativos e 34 opinativos.

Na Carta Capital, registraram-se 14 textos, todos opinativos, razão pela qual essa revista ficou fora desta etapa de análise do empírico, que está centrada no gênero informativo. A Época veiculou 12 textos, quatro informativos e oito opinativos. Já a IstoÉ publicou 33 textos, sendo 24 informativos e nove opinativos. Na Veja, foram nove textos, seis informativos e três opinativos.

A análise evidencia que Época recorreu a 13 entrevistados (sendo 11 Autoridades públicas e 2 Especialistas). Esse número é o mesmo quando se observa o uso das fontes Arquivos/Estudos. O tipo de fonte mais expressivo na cobertura da revista foi Documentos, com 32 ocorrências. Há um total de nove Declarações em função do cargo e oito registros de Fontes não especificadas/ identificadas. Além disso, identificou-se que a revista não ouviu cidadãos na cobertura de posse do novo mandatário.

IstoÉ trouxe 12 entrevistados distribuídos em seus materiais informativos: 5 Especialistas, 4 Autoridades públicas, 2 Cidadãos e 1 Celebridade. As Declarações em função do cargo representam o tipo de fonte mais presente na cobertura da revista, totalizando 16 ocorrências. Em seguida, Arquivos/Estudos e Documentos com 12 e 9 registros, respectivamente. Já as Fontes não especificadas/identificadas possuem sete ocorrências na revista, enquanto as Redes sociais foram utilizadas seis vezes.

A revista Veja foi a publicação que recorreu a mais entrevistados (27), sendo 18 Cidadãos, 1 Autoridade pública, 5 Especialistas e 3 Celebridades. Chama a atenção o alto número de Fontes não especificadas/identificadas na cobertura 
da revista (38). Na sequência, aparecem Arquivos/Estudos e Documentos com 25 e 18 ocorrências, respectivamente. O número de casos de Repórter observador também é considerável quando comparamos com os dados das outras duas revistas. Em Veja, esse tipo de fontes aparece 15 vezes.

Ao observarmos a quantidade e os tipos de fontes de informação utilizadas pelas três revistas - Época, IstoÉ e Veja -, considerando os três tipos de fontes com maior incidência em cada uma delas, tem-se que houve grande incidência do uso de fontes do tipo Documentos (59) (Quadro 2). Na sequência, aparecem as Fontes não especificadas/identificadas (53) e a categoria Entrevistados (52), composta majoritariamente por Cidadãos (20), seguidas de Autoridades Públicas (16), Especialistas (12) e Celebridades (4). Arquivos/Estudos aparecem na sequência (47). Em menor quantidade, o total geral nas três publicações ainda traz as Declarações em função do cargo e o Repórter observador, com 26 e 24 registros, respectivamente. Cidadãos representam a categoria de entrevistados mais ouvidos no conjunto geral dos dados, mas vale ressaltar que esse número se deve especialmente à cobertura de Veja, que ouviu esse tipo de fonte de maneira significativa.

Quadro 2: Fontes utilizadas na cobertura das revistas

\begin{tabular}{|l|c|c|c|c|}
\hline \multicolumn{1}{|c|}{ Tipos de fonte } & Época & Istoé & Veja & TOTAIS \\
\hline Documentos & 32 & 9 & 18 & 59 \\
\hline Fontes não especificadas & 8 & 7 & 38 & 53 \\
\hline Entrevistados & 13 & 12 & 27 & 52 \\
\hline Arquivos/Estudos & 13 & 12 & 25 & 50 \\
\hline Declarações em função do cargo & 9 & 16 & 1 & 26 \\
\hline Repórter observador & 3 & 6 & 15 & 24 \\
\hline Redes sociais & 3 & 6 & 8 & 17 \\
\hline Coletiva de imprensa & 0 & 5 & 0 & 5 \\
\hline Assessoria de imprensa & 1 & 2 & 2 & 5 \\
\hline Outros veículos/Outros jornalistas & 0 & 0 & 4 & 4 \\
\hline Agência de notícias & 0 & 0 & 0 & 0 \\
\hline
\end{tabular}

Fonte: elaborado pelas autoras.

Portais

Na cobertura jornalística dos portais $U O L$ e $G 1$, analisou-se um total de 86 materiais informativos publicados nos dias $1^{\circ}$ e 2 de janeiro de 2019. No G1, foram publicados 37 textos (32 notícias, três reportagens e duas notas), 
21 no dia da posse e 16 no dia seguinte. Já no portal UOL, foram 49 matérias publicadas nos dois dias, sendo 28 relativas à posse e 21 postadas no dia seguinte. A grande maioria dos textos do UOL se insere no gênero notícia; apenas quatro são reportagens, postadas no dia $1^{\circ}$ de janeiro.

O G1 recorreu a apenas sete entrevistados, sendo 3 Cidadãos, 2 Especialistas, 1 Autoridade pública e 1 Celebridade. A maior parte da cobertura do portal está ancorada nas impressões do Repórter observador, tipo de fonte que aparece 17 vezes. Em seguida, G1 ainda apresenta uso mais expressivo de Documentos (15), número superior ao uso de Arquivos/Estudos e Fontes não especificadas/ identificadas, que constam em 10 registros nos materiais observados. Em menor nível, o portal apresenta Redes sociais (6), Assessoria de imprensa (6) e Coletiva de imprensa (5).

Já em UOL, observou-se a presença de 36 entrevistados: 22 Cidadãos, 10 Autoridades públicas, 3 Especialistas e 1 Entrevistado não identificado. Documentos representam o tipo de fonte mais presente na cobertura do portal, com 23 registros. Na sequência, Assessoria de imprensa e Redes sociais aparecem empatadas, com 26 ocorrências. UOL incorpora o Repórter observador como fonte 17 vezes, mesmo número observado em G1. As Fontes não especificadas/identificadas e Arquivos/ Estudos contabilizam, respectivamente, 14 e 10 registros na cobertura do UOL.

O quadro geral das fontes acionadas pelo G1 e UOL (Quadro 3) mostra que os tipos mais predominantes em ambos os portais e nos dois dias da cobertura foram Documentos (47). Na sequência aparecem Entrevistados (43). Tal categoria inclui Cidadãos (25), Autoridades Públicas (11), Especialistas (5), Celebridades (1) e Entrevistado não identificado (1). Logo depois, tem-se a presença de Repórter observador (34), Redes sociais (32) e Assessoria (26). Na comparação entre os dois portais, chama a atenção o fato de o UOL ter utilizado muito mais fontes do tipo Documentos (32), Redes sociais (26) e Cidadãos (22). Já a predominância de fontes no $G 1$ está em Repórter observador (17) e Documentos (15), seguidos por Pesquisas, Assessoria e Fontes não especificadas/identificadas, empatadas em terceiro lugar (10). 
Quadro 3: Fontes utilizadas na cobertura dos portais

\begin{tabular}{|l|c|c|c|}
\hline \multicolumn{1}{|c|}{ Tipos de fonte } & G1 & UOL & TOTAIS \\
\hline Documentos & 15 & 32 & 47 \\
\hline Entrevistados & 7 & 36 & 43 \\
\hline Repórter observador & 17 & 17 & 34 \\
\hline Redes sociais & 6 & 26 & 32 \\
\hline Assessoria de imprensa & 6 & 26 & 26 \\
\hline Fontes não especificadas & 10 & 14 & 24 \\
\hline Arquivos/Estudos & 10 & 10 & 20 \\
\hline Outros veículos/Outros jornalistas & 3 & 5 & 8 \\
\hline Coletiva de imprensa & 5 & 0 & 5 \\
\hline Declarações em função do cargo & 0 & 0 & 0 \\
\hline Agência de notícias & 0 & 0 & 0 \\
\hline
\end{tabular}

Fonte: elaborado pelas autoras.

\section{Hegemonia do oficialismo, baixa participação da sociedade civil e fontes ocultas}

A análise interpretativa dos dados focaliza os três maiores problemas identificados na cobertura da posse de Jair Bolsonaro nas mídias jornalísticas estudadas. Com base nos resultados obtidos no mapeamento das fontes nos materiais informativos dos jornais, revistas e portais e também na discussão teórica realizada, três eixos temáticos são destacados e discutidos a seguir: a hegemonia das fontes oficiais; a baixa participação de atores da sociedade civil; e o problema das fontes ocultadas.

\section{A hegemonia das fontes oficiais}

A cobertura dos jornais analisados reafirmou o grande espaço historicamente concedido às fontes oficiais no jornalismo brasileiro, especialmente quando se trata de temas e acontecimentos políticos. Juntos, os três impressos recorreram a 51 Autoridades públicas entre os entrevistados. O oficialismo das fontes foi marcado por entrevistas com diversos tipos de autoridades públicas, com destaque, em geral, a interlocutores governamentais, dentre eles membros dos poderes Executivo e Judiciário, generais chamados para integrar o novo governo e integrantes da Polícia Federal e Polícia Civil. A maior parte das falas dessas fontes escolhidas, como já esperado, refletiu posicionamentos pouco críticos em relação ao perfil político e às ideias e planos do presidente eleito. 
Na Folha de S.Paulo, as Autoridades públicas foram as fontes mais entrevistadas (19). Também O Estado de S. Paulo entrevistou mais Autoridades públicas (19) do que Cidadãos (17) e Especialistas (14), e fez uso expressivo de Documentos com caráter oficial (20). O oficialismo das fontes ainda foi notável em O Globo, embora neste jornal as Autoridades públicas (13) tenham sido menos entrevistadas do que os Especialistas (17). Nos três veículos, somaram-se a este caráter de vozes oficiais os muitos registros de Documentos (39), na maior parte das vezes informações retiradas de discursos e pronunciamentos oficiais ou de medidas provisórias, decretos e leis.

A cobertura das revistas semanais analisadas também é conformada por um forte caráter oficial. Nesse caso, predominam no conjunto geral das publicações, sobretudo as fontes do tipo Documentos (59), que congregam várias menções aos pronunciamentos do presidente ou da equipe de governo. O tom oficial ainda aparece, em menor escala, entre os entrevistados da categoria Autoridades públicas (16). Esse tipo de fonte foi a terceira mais observada em Época, e a maioria das autoridades é composta por homens. A revista ainda traz um número expressivo de Documentos (32).

IstoÉ apresenta fontes oficiais de modo menos significativo comparado à Época: Documentos (9) e Autoridades públicas (4). Na edição de dezembro, que traz informações captadas antes da posse presidencial e da entrada do novo governo, há destaque para uma entrevista exclusiva com o então futuro ministro da Casa Civil Onyx Lorenzoni, o qual dá o tom do que seria o discurso do governo Bolsonaro, com destaques como defesa do combate à corrupção, plano de governo simples - sem influência de marqueteiros -, enxugamento do Estado/desburocratização e reforma da Previdência como urgência. Em Veja, o oficialismo também se manifesta mais explicitamente no uso de Documentos (18). A cobertura da publicação apresenta apenas uma Autoridade pública devidamente designada, mas é preciso sublinhar que muitas das fontes oficiais aparecem de modo não especificado, como será destacado mais adiante. 
Na cobertura dos portais também foi observada uma dependência de fontes oficiais. G1 e UOL trazem um alto número de Documentos (47), além de utilizarem informações originadas em Assessorias de imprensa (26), entrevistas com Autoridades públicas (11) e Coletivas de imprensa (5). Boa parte dos documentos limita-se a trechos dos discursos oficiais pronunciados por Jair Bolsonaro ou ministros empossados, citados nas matérias sem contraposição ou repercussão junto a outras fontes da sociedade. Do mesmo modo, a recorrente menção a informações e declarações de autoridades via redes sociais digitais, especialmente Twitter, pode ser vista também como uma nova forma de expressão de fontes jornalísticas oficiais.

Como mostram alguns pesquisadores (RIZZOTTO et al., 2019; ZAGO, 2010; ZILLER; TEXEIRA, 2018), em tese, as redes digitais podem servir como fontes para potencializar entendimentos sobre os fatos e abordagens, para além das posições oficiais, ampliando o debate público. Todavia, na prática, a inserção dessas posições diversas nos conteúdos da cobertura da política continua passando pelo filtro político-ideológico das linhas editoriais das mídias e/ou de concepções pessoais de jornalistas na escolha das fontes e das falas que ganharão visibilidade. No G1, as autoridades entrevistadas falaram sobre o trivial da cerimônia: o número de participantes, de jornalistas e de agentes de segurança no evento ou ainda acerca da organização da posse em geral. No UOL, as autoridades ouvidas eram principalmente parlamentares aliados de Bolsonaro. É o caso dos senadores Flávio Bolsonaro (PR) e Major Olímpio (PSL), dos deputados Eduardo Bolsonaro e Rubens Bueno (PPS) e do prefeito de Salvador, ACM Neto (DEM).

\section{A baixa participação de atores da sociedade civil}

Nos três jornais analisados, atores da sociedade civil são representados sobretudo pelas fontes do tipo Cidadãos (30) e Especialistas (34). A Folha de S.Paulo foi quem mais ouviu cidadãos (17), logo após as Autoridades públicas (19). A presença dos cidadãos foi bem mais rara n'O Estado de. S. Paulo (8) e n'O Globo (5). Além do espaço reduzido para os Cidadãos, observa-se que esse 
tipo de fonte está distribuído em um reduzido número de materiais informativos. Notou-se ainda que a maioria dos depoimentos desses indivíduos era composto por apoiadores de Bolsonaro, reforçando percepções e expectativas positivas acerca do presidente eleito.

As pessoas comuns ouvidas na cobertura dos impressos estavam, em geral, inseridas nas caravanas organizadas para acompanhar a posse na Esplanada dos Ministérios, como membros de igrejas neopentecostais, donas de casa, servidores públicos e estudantes - vários deles identificados pelos jornais como participantes de movimentos políticos da direita nacional. Já a categoria Especialistas aparece com mais força em O Globo (17), e a maioria dos experts advém do campo econômico. De maneira geral, o lugar concedido para ouvir cidadãos comuns, profissionais, especialistas do campo político ou econômico, acadêmicos ou integrantes de movimentos sociais contrários ao novo governo foi praticamente nulo.

Nas revistas, a sociedade civil também se manifesta a partir da presença de Cidadãos (20) e Especialistas (12), e, dentre as três publicações analisadas, a cobertura de Veja foi a que notavelmente ampliou a voz de Cidadãos (18). Porém, cabe observar que nenhuma dessas fontes é identificada pelo nome, bem como nenhum dos milhares de espectadores da posse é entrevistado individualmente. Assim como não há espaço para a fala dos cidadãos além de apoiadores/as que foram à cerimônia de posse, houve pouca recorrência a fontes especializadas por parte das revistas.

Levando em conta as características de veículos como revistas, que permitem textos mais interpretativos, era de se esperar um esforço de cobertura que abrangesse, por exemplo, ex-funcionários, colegas de quartel ou outras pessoas próximas que ajudassem a compreender a atuação política e militar de Jair Bolsonaro, capitão graduado pela Academia Militar Agulhas Negras, vereador e deputado por quase três décadas. Nem mesmo uma pesquisa em sua atuação parlamentar parece ter sido realizada, o que pode sinalizar o endosso à postura de outsider sustentada pelo candidato durante a campanha de 2018 ou uma tentativa de ocultar a pouca relevância dos serviços públicos por ele prestados. 
A cobertura dos portais também é composta por uma baixa diversidade de atores da sociedade civil. Em G1 e UOL, os Cidadãos (25) e Especialistas (5) entrevistados não refletem uma pluralidade de perspectivas. Sem investimento em pré-apuração, ambos os portais priorizaram amplificar a voz de quem estava facilmente disponível no local das ocorrências: alguns cidadãos e o discurso oficial dos empossados - Jair Bolsonaro e seus ministros. No caso do G1, três dos seis entrevistados eram cidadãos comuns e todos esses indivíduos eram apoiadores do novo governo. Suas falas foram meramente protocolares, sem aprofundamento a respeito do apoio e expectativas em relação ao novo governo. Os modos de expressão desse tipo de fonte foram semelhantes no $U O L$, embora esse veículo as tenha trazido em quantidade muito maior (32), concentradas em apenas quatro matérias.

Nos portais praticamente inexistiram entrevistas com atores de partidos de oposição e nem com especialistas (cientistas políticos, sociólogos etc.). No G1, uma das exceções, em termos de diversidade de fontes mobilizadas, foi a matéria sobre as mudanças na Fundação Nacional do Índio (Funai) e no Instituto Nacional de Colonização e Reforma Agrária (Incra), publicada no dia 2 de janeiro, com o título "Bolsonaro transfere para a Agricultura a demarcação de terras indígenas e quilombolas". Nela, o portal utilizou três fontes, mostrando posicionamento crítico desses atores ao ato do novo governo já empossado: o Greenpeace Brasil, o Conselho Indigenista Missionário (Cimi) e a Comissão Pastoral da Terra (CPT).

\section{As fontes ocultadas}

As fontes ocultadas, isto é, aquelas não especificadas ou identificadas, também foram um problema comum às três categorias de mídias analisadas neste estudo (jornais, revistas e portais). Elas compõem parte significativa da cobertura dos três jornais. Do total de 148 pessoas ouvidas, as fontes não identificadas somam 33 ocorrências. O ocultamento das fontes é bastante evidente em O Estado de S. Paulo (14), em que foi o terceiro tipo com mais registros depois de Documentos (20) e Autoridades públicas (19). Um exemplo desse fenômeno 
pode ser visto na situação em que uma informação entre aspas é creditada a "um dos generais do grupo de sete que vai integrar a administração". O Globo também reúne um número expressivo de Fontes não especificadas/identificadas (13), mesma quantidade de Autoridades públicas entrevistadas, dando informações atribuídas genericamente a interlocutores, auxiliares e integrantes da equipe de Bolsonaro. Na Folha de S.Paulo, as fontes ocultadas estão distribuídas em quatro materiais informativos e em número consideravelmente menor (6) se comparado aos outros dois jornais analisados.

Dentre as revistas semanais de informação, chama a atenção o alto número de fontes ocultadas (53). A cobertura da revista Veja é a que possui a mais alta incidência: 38. Alguns desses registros são passíveis de suposição; por exemplo, na primeira edição de janeiro de 2019, no infográfico sobre as patentes do Exército, que evidencia hierarquias e símbolos militares que integram o estilo de vida do capitão reformado recém-eleito. A fonte das informações não é mencionada, entretanto, supõe-se que elas tenham sido extraídas do site oficial das Forças Armadas. Já na revista Época, as fontes ocultadas não tiveram tanta incidência (8). A revista referiu-se tanto a certas "entidades", sem nomeá-las, quanto a dados não explicitados sobre o "déficit na casa dos 290 bilhões" para argumentar em favor da Reforma da Previdência. Tal categoria de fontes também apareceu com menos ênfase em IstoÉ (7), sobretudo na reportagem principal sobre o novo governo, que não cita as origens das informações.

O ocultamento das fontes ainda é um fenômeno notável na cobertura dos portais (24), com 14 registros no $G 1$ e 10 no UOL. Vale ressaltar que as Fontes não especificadas/identificadas não se referem àqueles casos em que os jornalistas recorrem ao garantido direito de sigilo da fonte. Elas incluem, na verdade, informações retiradas de outras fontes, como assessoria de imprensa, outras mídias jornalísticas e sites institucionais, informação já dada pelo próprio veículo, conversas de bastidores com autoridades públicas ou em entrevistas coletivas, e não devidamente especificadas na matéria jornalística, por descuido ou mesmo propositalmente. Tal prática pode apontar para a falta de transparência 
com o leitor, que não fica sabendo de onde foi retirada a informação, uma falta que compromete também a qualidade e credibilidade da informação jornalística.

\section{Considerações finais}

A análise empreendida neste estudo mostra, em resposta à questão que orientou o trabalho, o modo como a seleção das fontes condicionou o resultado da cobertura da posse presidencial de Jair Bolsonaro nos três tipos de mídia analisados. A cobertura tem um forte caráter oficial, aspecto que resulta sobretudo da lógica imperante na seleção das fontes. Priorizou depoimentos de autoridades públicas, uso de documentos, especialmente discursos de posse, além de informações de assessorias de imprensa e de entrevistas coletivas. A dependência e o espaço dado às posições e visões oficiais restringiram a cobertura a um fazer jornalístico acomodado, burocrático e declaratório.

Além disso, o lugar reduzido para expressões de outros atores da sociedade civil, como cidadãos comuns e representantes de movimentos sociais variados, consolida uma cobertura e uma narrativa acrítica sobre a posse, com baixa diversidade identitária e pluralidade interpretativa acerca dos significados do novo governo e de suas políticas. A inserção efetiva de outros agentes e perspectivas, sobretudo as oposições ao novo mandatário, tornaria a cobertura mais plural, crítica e mais representativa do que é a sociedade brasileira, com seus entendimentos diferentes, até opostos e conflitantes, em torno de acontecimentos e questões públicas que a afetam. Se o contexto político e social brasileiro foi marcado pela radicalização política, sobretudo desde o golpe que afastou Dilma Rousseff da presidência da República e suas repercussões na eleição de Jair Bolsonaro, em 2018, essa polarização e divergências não reverberaram na cobertura de um acontecimento relevante como uma posse presidencial. Na contramão do necessário contraditório, os três tipos de mídia destacam um aparente consenso em torno dos fatos narrados, visto que se limitaram a fontes oficiais que então chegavam ao poder. 
A exclusão de outros atores ajuda a construir a equivocada impressão de que a harmonia social reinava no país no período da posse de Jair Bolsonaro. Assim, as práticas de seleção e apresentação das fontes observadas nos jornais, revistas e portais colaboram para evidenciar uma cobertura que, em grande medida, apaga as diferenças, banaliza o acontecimento pautado e despolitiza o debate sobre várias questões de interesse público que envolvem o começo de um novo governo. Em especial, quando a nova gestão está sob o comando de um representante da extrema-direita política, cujo desrespeito a direitos humanos e regras democráticas básicas é amplamente conhecido há anos, inclusive por parte das mídias jornalísticas aqui analisadas.

A falta de investimento na pré-apuração de informações sobre a posse de Bolsonaro - seja por conta da precarização do trabalho nas empresas jornalísticas, acomodação profissional e/ou decisão política editorial - resultou numa cobertura precária, pouco crítica e centrada na extrema factualidade (SILVA et al., 2020). Acionando fontes facilmente disponíveis para apuração na véspera ou no dia do acontecimento - autoridades, assessorias, discursos oficiais, apoiadores do novo governo, outras mídias etc. -, a cobertura passou distante de informações esperadas da imprensa no tratamento de um acontecimento programado do porte de uma posse presidencial. É o caso da falta de informação ampliada sobre a trajetória, atuação e posicionamentos do novo mandatário, bem como do pouco destaque a políticas propostas por seu governo nas diversas áreas - educação, saúde, meio ambiente, reformas Trabalhista e da Previdência etc.

A escolha de fontes é, como nos lembra Cremilda Medina (1986), a grande empreitada de toda pauta jornalística. O silenciamento promovido pela cobertura a outros atores de espectro político diferente ao do novo governo - políticos profissionais ou cidadãos comuns - e também de especialistas de áreas diversas é um fator central a explicar os limites da cobertura e dos conteúdos divulgados e aqui analisados, nos quais não há marcas de vozes mais críticas e questionadoras do perfil político, das ideias e propostas de Jair Bolsonaro. 
Se o jornalismo é um espaço da expressão do interesse público e da cidadania, conforme o discurso de autolegitimação, e se a pluralidade de fontes e de perspectivas é uma condição fundamental para a discussão sobre o que é do interesse dos cidadãos, isso não se evidencia na realidade empírica aqui estudada - a cobertura da posse de Jair Bolsonaro por mídias jornalísticas hegemônicas. O estudo realizado corrobora uma tradição de pesquisas, apontando a hegemonia de fontes oficiais e do poder na definição e interpretação do que é assunto de interesse público.

\section{Referências}

ALSINA, M. R. A construção da notícia. Petrópolis: Vozes, 2009.

ALTHUSSER, L. Aparelhos ideológicos de Estado. 7a. ed. Rio de Janeiro: Graal, 1998.

BLUMER, J.; GUREVITCH, M. The crisis of public communication. Routledge. London, 1995.

CHARAUDEAU, P. Discurso das mídias. São Paulo: Contexto, 2006.

COLOMBO, F. Conhecer o jornalismo hoje: como se faz a informação. Lisboa: Presença, 1998.

CURRAN, J. Rethinking mass communication. In: CURRAN, J.; MORLEY, D. ; ALKERDINE, V. (ed.). Cultural studies and communications. London: Arnold, 1996.

GANS, H. Deciding what's news: a study of CBS evening news, NBC nightly news, newsweek, and time. Evanston: Northwestern University Press, 1979. 
GOMES, W. Jornalismo, fatos e interesses - ensaios de teoria do jornalismo. Florianópolis: Insular, 2009.

HALL, S.; CHRITCHER, C. JEFFERSON, T.; CLARKE, J.; ROBERTS, B. A produção social das notícias: o mugging nos media. In: TRAQUINA, N. (org.) Jornalismo: questões, teorias e "estórias". Lisboa: Vega, 1993. p. 224-248.

JAUREGUI, C. Instrumento de ação jornalística - processos de entrevista. In: LEAL, B. (org.). Formação em Jornalismo: da prospecção dos acontecimentos à edição. Belo Horizonte: Editora UFMG, 2018. p. 49-60.

KUNCZIK, M. Conceitos de jornalismo: Norte e Sul. São Paulo: Edusp, 2001.

LASHMAR, P. Sources and Source Relations. In: VOS, T. \& HANUSCH, F. (org.) The International Encyclopedia of Journalism Studies. New York: Editora John Wiley \& Sons, 2019.

MAIA, R. Mídia e deliberação. Atores críticos e o uso público da razão. In: MAIA, R.; CASTRO, M. C. P. S. (org.). Mídia, esfera pública e identidades coletivas. Belo Horizonte: Editora UFMG, 2006. p. 153-179.

MEDINA, C. Entrevista: o diálogo possível. São Paulo: Summus, 1986.

MOTTA, L. G. Imprensa e poder. In: MOTTA, L. G. (org.). Imprensa e poder. Brasília, DF: Editora da Universidade de Brasília; São Paulo: Imprensa Oficial do Estado, 2002. p. 13-28.

PINTO, M. Fontes jornalísticas: contributos para o mapeamento do campo. Comunicação e Sociedade 2, Braga, v. 14, n. 1-2, p. 277-294, 2000. 
PINTO, R. J. The evolution of the structure of political journalism in four "quality" newspapers (1970-1995). Tese (Doutorado) - Universidade de Sussex, Reino Unido, 1997.

RIZZOTTO, C.; SARAIVA, A.; NASCIMENTO, L. \#ELENÃO: conversação política em rede e trama discursiva do movimento contra Bolsonaro no Twitter. In: ENCONTRO ANUAL DA COMPÓS, 28., 2019, Porto Alegre. Anais [...]. Porto Alegre: Compós.

SANT'ANA, F. Mídia das fontes: um novo ator no cenário jornalístico brasileiro. Um olhar sobre a ação midiática do Senado Federal. Brasília, DF: Edições Técnicas do Senado Federal, 2009.

SANTOS, R. A negociação entre jornalistas e fontes. Coimbra: Minerva, 1997.

SCHLESINGER, P. Repenser la sociologie du journalisme: les stratégies de la source d'information et les limites du média-centrisme. Réseaux, Paris, v. 10, n. 51 , p. 75-98, 1992.

SIGAL, L. Reporters and officials: the organization and politics of newsmaking. Lexington: D. C. Heath, 1973.

SILVA, G. ; SILVA, T; BERTASSO, D. ; SILVA, V. N.; GUSTAFSON, J. ; AZEVEDO, D. Análise da apuração jornalística da posse de Jair Bolsonaro. Novos Olhares, São Paulo, v. 9, n. 2, p. 7-20, 2020. DOI: https://doi.org/10.11606/issn.2238-7714. no.2020.172488.

SOUSA, J. P. Teorias da notícia e do jornalismo. Chapecó: Argos, 2002.

TRAQUINA, N. Teorias do jornalismo. A tribo jornalística - uma comunidade interpretativa transnacional. Florianópolis: Insular, 2005. v. 2. 
TUCHMAN, G. La producción de la noticia. Estudio sobre la construcción de la realidad. Barcelona: Gustavo Gili, 1983.

ZAGO, G. S. O Twitter como fonte e pauta de notícias na mídia online de referência. In: CONGRESSO BRASILEIRO DE CIÊNCIAS DA COMUNICAÇÃO, 32., 2010, Caxias do Sul. Anais [...]. Caxias do Sul: Intercom.

ZILLER, J.; TEXEIRA, N. Instrumento de ação jornalística - processos de pesquisa e apuração. In: LEAL, B. (org.). Formação em Jornalismo: da prospeç̧ão dos acontecimentos à edição. Belo Horizonte: Editora da UFMG, 2018. p. 41-48.

submetido em: 7 jul. 2021 | aprovado em: 30 set. 2021 